\title{
FOREIGN INVESTORS VERSUS HOST COMMUNITIES: AN URBAN POLITICAL ECONOMY MODEL FOR TOURIST CITIES
}

By developing an urban political economy model for tourist cities that considers the side effects and a city's carrying capacity for tourism, this paper shows how foreign investors and a host community's interests and preferences on the openness of the city greatly diverge. Foreign investors have the tendency to influence a city's policy toward more openness than optimal. If foreign investors' interest is overly represented in a city's policymaking, the city may not be able to a follow a rational development strategy. Macao is adopted as a case study.

Keywords: foreign investor, host community, side effects, bargaining

DOI: $10.15611 /$ aoe.2018.2.11

\section{INTRODUCTION}

Based on the assumption that inter-city competition for foreign investment is escalating, market fundamentalists advocate cities to create market conditions that attract foreign investors to invest in and exploit local competitive advantages. The desirability of foreign investment is backed by a large volume of economic literature. According to these studies, foreign capital inflow has various advantages such as promoting growth, fostering competition, transferring technology and management skill, enhancing policy transparency and market discipline, strengthening efficiency in financial institutions, and smoothing inter-temporal consumption across cities (Choi and Harrigan 2008, Hill 1990, and Rho and Rodrigue 2015). However, quite a number of studies bear witness to the serious side effects accompanying the overgrowth of tourism, which is largely driven by foreign investment. The economic side effects can be observed in leakage, the increased cost of living, and asset bubbles; the environmental side effects can be observed in air pollution, noise pollution, and the overuse of natural resources; the social side effects can be observed in increased crime, social polarization, and cultural alienation (Boukas and Ziakas 2013, Winters, Corral and Mora 2013, and Lew, Hall and Williams 2008).

\footnotetext{
* Faculty of Social Sciences, University of Macau, China.
} 
In order to address the problem at its root, the authors, by focusing on the different preferences of foreign investors and host communities, try to develop an urban political economy model for tourist cities to illustrate how the interests of foreign investors and host communities might diverge in the presence of significant side effects. We focus specifically on a city's degree of openness to capital, tourist visitors and immigration, and show the possible negative impacts of foreign investments. After theoretical modeling, the case study of Macao is presented, giving some support to the theoretical construct since Macao, a booming tourist city, while experiencing spectacular growth since its gaming sector was liberalized to foreign investors, has been suffering from serious socio-economic side effects. By critically reevaluating the possible negative political impacts of massive foreign capital inflow, this paper tries to balance the prevailing rather onesided views in the existing literature and inspire city planners to formulate more comprehensive foreign investment policies.

\section{AN URBAN POLITICAL ECONOMY MODEL FOR TOURIST CITIES}

For a given tourist city, openness is denoted as $a$, ranging from 0 (pure closed) to 1 (pure open). By openness we refer to whether the principal city development strategy orientation is open, closed, or moderate (between the two extremes). An open strategy, usually driven by the simple belief that 'more is better', can be seen in an indiscriminately open and welcome attitude towards incoming tourists, foreign investments, and tourism-related immigration. A closed strategy, on the contrary, may be seen as a reluctance to open the city up to foreign factors of production or foreign consumers. However, the openness and non-openness are really comparative terms and their pure forms are rarely seen in reality and are only used for theoretical construction. Admittedly, a city's openness provides a certain opportunity for economic growth (average growth denoted by $g$ ). Yet this opportunity is a double-edged sword since the city's openness and consequent tourism growth could lead to various side effects.

Tourism carrying capacity is defined as the maximum number of tourists that can visit a location at the same time without causing destruction to the city's physical, economic, or socio-cultural environment or an unacceptable decrease in the quality of satisfaction of both residents and visitors. The tourism carrying capacities of a city may vary greatly for the same amount of tourist arrivals. While cities with a limited carrying capacity may 
experience severe side effects, cities with a large carrying capacity can accommodate large numbers of tourists without suffering from significant side effects. We denote $b$ as the vulnerability of a city to side effects, ranging from 0 (the least vulnerable) to $l$ (the most vulnerable). Obviously, vulnerability is negatively related to the city's tourism carrying capacity.

Finally, we denote the severity of side effects as $\sigma$. We have the side effects function $\sigma=\sigma(a, b)$, where $\frac{\partial \sigma}{\partial \alpha}>0$ and $\frac{\partial \sigma}{\partial b}>0$, i.e. the more open the city is and the more vulnerable to side effects, the higher the severity of side effects. Note that $\sigma=\sigma(a, b)$ can be rewritten as $\sigma=\sigma_{b}(a)$ by taking $b$ as a parameter, and is assumed to be continuously differentiable so that it is mathematically legitimate to have a variant of this relation such as $\alpha=a_{\sigma}(b)$ or $a=a_{b}(\sigma)$. The side effects function $\sigma=\sigma(a, b)$ or $\sigma=\sigma_{b}(a)$ along with its variant $a=a_{b}(\sigma)$ is depicted in the two panels of Figure 1 .

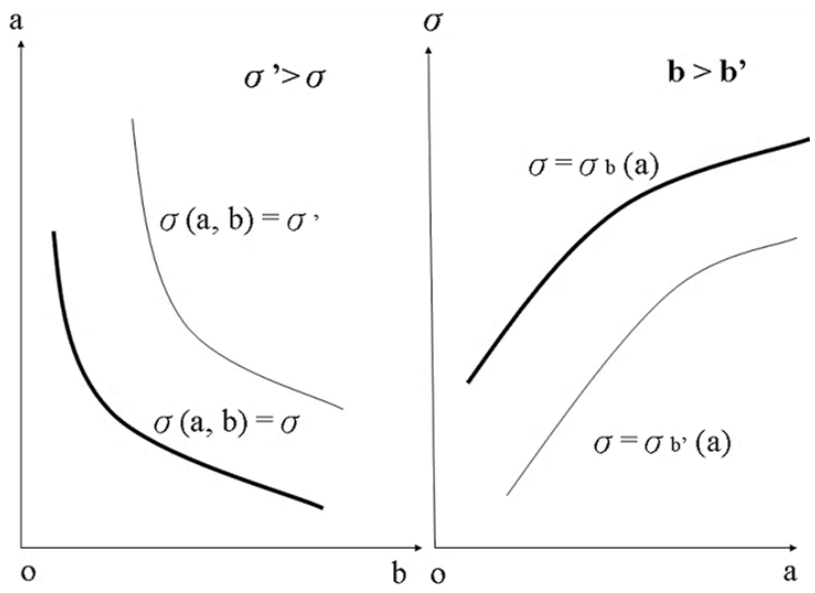

Figure 1. Side effects influenced by openness and vulnerability

Source: Sheng, L. (2012) Rethinking the Impacts of Foreign Investors on Urban Development: The City of Macao. "Annals of Regional Science”, 49(1), 73-86. Figure 2.

Normally the average economic growth $g$ initially increases with more tourist arrivals, foreign investment, and tourism-related immigration (permitted by larger $a$ ), then it reaches a maximum at a certain level of openness $a_{m} \quad\left(0<a_{m}<1\right)$. Finally, it decreases as tourists, foreign investment and foreign labor continue to flow in (excess openness with 
too large $a$ ); namely, $g=G(a)$, where $G^{\prime}(\cdot)>0$ for $a<a_{m}$ and $G^{\prime}(\cdot)<0$ for $a>a_{m}$. A variant of the side effects function, $a=a_{b}(\sigma)$, can be used to convert the relationship of economic growth to openness, $g=G(a)$, into a relation between growth and side effects, $g=g_{b}(\sigma)$, in such a way that $g=G(a)=G\left(a_{b}(\sigma)\right)=g_{b}(\sigma)$. Alternatively, one may differentiate $g=G(a)$ and $\sigma=\sigma_{b}(a)$ to find the derivative of $g=g_{b}(\sigma)$ in the form of $\frac{\mathrm{dg}}{\mathrm{d} \sigma}=\frac{G^{\prime}(a)}{\sigma_{b^{\prime}}(a)}>$ (or $<$ ) 0 for $a<$ (or $>$ ) $a_{m}$. The opportunity function $g=g_{b}(\sigma)$ is depicted in Figure 2, where each point on the opportunity curve (concave) $g_{b}(\sigma)$ is associated with a different sets of tourist visitors, foreign investment, and foreign labor allowed by a certain degree of openness $a$. The shape of an opportunity curve is city-specific, depending on a city's capacity to utilize tourists, foreign investment, and foreign labor to promote economic growth as well as its ability to manage the accompanying side effects.

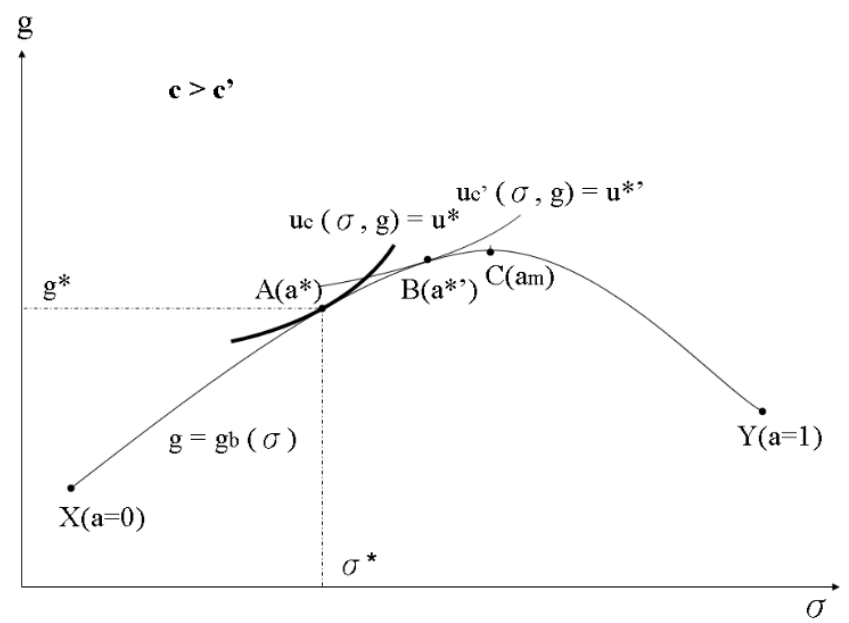

Figure 2. Diagram of average growth and side effects

Source: Sheng, L. (2011) Theorizing Free Capital Mobility: A Perspective on Developing Economies. "Review of International Studies", 37(5), 2519-2534. Figure 1.

The preference of a city (indexed by $c$ ) for risky opportunities can be captured by an aggregate utility function that takes economic growth $g$ as a good and side effects $\sigma$ as a bad; namely, $u=u_{c}(\sigma, g)$, where $\frac{\partial u_{c}}{\partial \sigma}<0$ and 
$\frac{\partial u_{c}}{\partial \mathrm{g}}>0$, with $(\sigma, g)$ treated as objects of choice and $c$ as the city index.

An indifference curve (convex) associated with this function is a subjective set of tradeoffs between side effects and growth by the city, and only one of the city's indifference curves is tangent to its opportunity curve. The tangency point $A$ gives the optimal decision on side-effect-growth tradeoffs $\left(\sigma^{*}, g^{*}\right)$ and its optimal choice of openness $a^{*}$. All these policy variables are affected by underlying economic parameters such as vulnerability of the city to side effects $b$ and preference relations $c$; that is, $\sigma^{*}=\sigma(b, c)$, $g^{*}=g(b, c)$, and $a^{*}=a(b, c)$.

Different cities usually have different attitudes towards side effects, reflected in differently shaped indifference curves. For a poor city suffering from widespread poverty, the local government may be inclined to pursue rapid growth by permitting massive tourism, foreign investment and foreign labor despite the potential risks. Suppose this city has a lower value of $c$ representing its policy preferences, i.e. more growth-prone and less side effects-averse. The city should then have a flatter set of indifference curves (shown by the thin line in Figure 2). As a result, the optimal tradeoff for this city will be at point $B$, with more side effects and faster growth made possible by increased tourism, foreign investment and foreign labor under a wider openness standard. One sees for this situation that $\frac{\partial \sigma^{*}}{\partial c}<0, \frac{\partial g^{*}}{\partial c}<0$, and $\frac{\partial a^{*}}{\partial c}<0$. This shows that increased side effects are the inevitable price paid for higher growth under the more liberal openness policy.

Under normal circumstances, it is easy to establish that $\frac{\partial \sigma^{*}}{\partial c}>0, \frac{\partial g^{*}}{\partial c}<0$, and $\frac{\partial a^{*}}{\partial c}<0\left(\frac{\mathrm{d} g *}{\mathrm{~d} \sigma^{*}}<0\right.$ through the $b$-channel, a substitutable relationship between $\sigma^{*}$ and $g^{*}$ ). Some of these results can be derived from diagrammatical manipulation (as in Figure 3) by combining the two panels of Figure 1 and some part of Figure 2 through the parameterization of tradeoff choices with $b$, and by incorporating the desired relationship between $g^{*}$ and $b$. The results from Figure 3 intuitively show that an improved tourism carrying capacity (lower $b$ ) is a necessary condition for a city's government to pursue greater openness (greater $a^{*}$ ) while enjoying fewer side effects (lower $\sigma^{*}$ ) and stronger growth (higher $g^{*}$ ). In other words, it is rational for a city to tighten 
its control over the inflow of foreign factors of production in order to avoid large side effects if its tourism carrying capacity is not large enough to cope with massive inflows of tourism, foreign investment, and foreign labor. Cities may make different tradeoffs at the optimum because of their differing conditions and policy preferences. Each city has a different combination of opportunity and utility parameters $(b$ and $c)$.

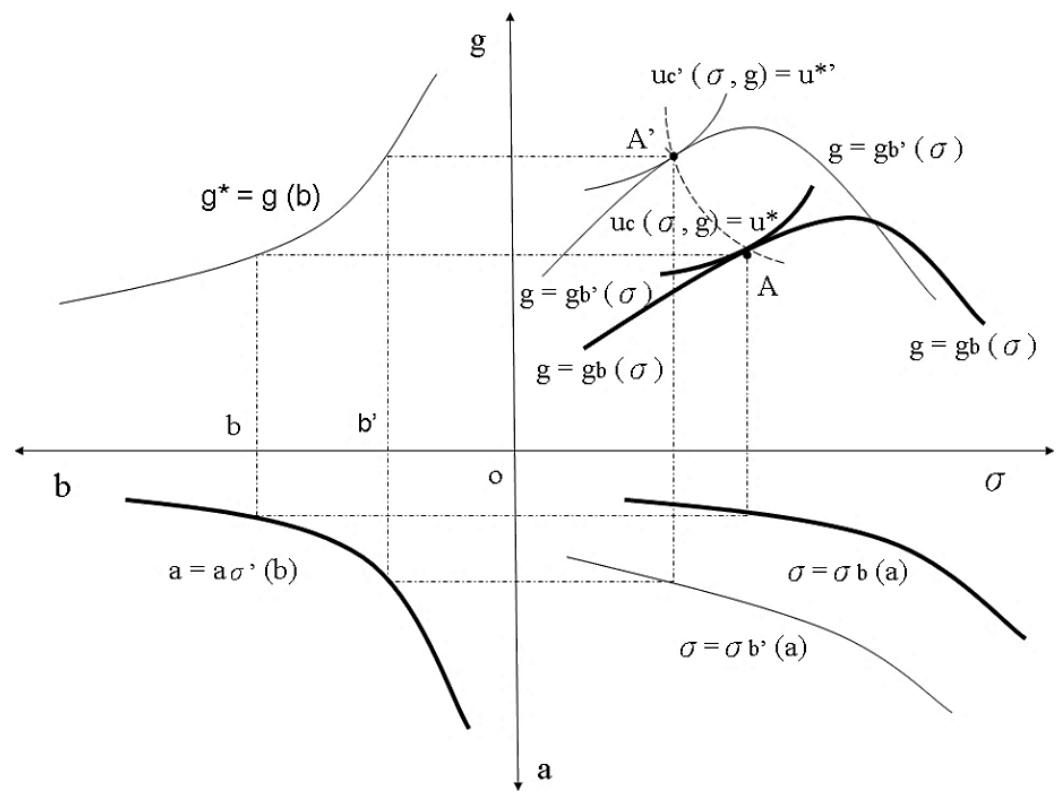

Figure 3. Effects of long-term changes on tradeoff choices

Source: Sheng, L. (2011) Theorizing Free Capital Mobility: A Perspective on Developing Economies. "Review of International Studies", 37(5), 2519-2534. Figure 2.

Now consider a typical capital-rich foreign investor $B$ ready to invest in tourism. If the investor's capital is free to enter an opportunity-rich tourist city $A$, it might engage in real estate and financial speculation for quick returns or carry out direct investment in real projects for profit, all of which promotes welfare for $B$. Yet a higher value of $a$, representing more openness, implies a greater risk of side effects in $A$. But as 'guest' $B$ only marginally shoulders the side effects for $A$ in the long-term, more openness by $A$ will continue to benefit $\mathrm{B}$ until the point that the resulting troubles will also adversely affect $B$. We can imagine in the extreme case of full openness that these consequences might include a chaotic situation with severe side effects for $A$ that are also disastrous for $B$ as it may not be able to withdraw what it invested in A. 
Foreign investor B's opportunity function $g=G_{B}(a)$ is assumed to increase first with $A$ 's openness, then reach a peak at $a_{B}$ (shown in Figure 4), and finally decline if wide openness causes enough trouble to adversely affect $B$. This function can be changed to the equivalent form of $g=g_{B}(\sigma)$ since the side effects faced by $B, \sigma=\sigma_{B}(a)$ rise with $a$, though not greatly. The opportunity curve (shown as a thick line in Figure 4 ), $g_{B}(\sigma)$, is also concave and peaks at $\sigma_{B}=\sigma_{B}\left(a_{B}\right)$. Note that this curve largely lies below the curve for $A$ (thin concave) according to Solow's growth theory and supported by empirical evidence that economies lacking in capital grow faster if openness is not too risky (before the $a^{\prime}$ point). If $A$ opens too widely (i.e. $a>a^{\prime}$ ), growth opportunities will turn worse for $A$ than for $B$ (i.e. $g_{A}(\sigma)<g_{B}(\sigma)$ for $\left.\sigma>\sigma^{\prime}\right)$. In addition, foreign investor $B$ 's utility function $u=u_{B}(\sigma, g)$ has the same properties as $A$ 's (thin), i.e. the former's indifference curves (thick) are also convex and upward sloping. Yet indifference curves are flatter for $B$ than for $A$ since $B$ is less side effectsaverse and more growth-prone than the latter.

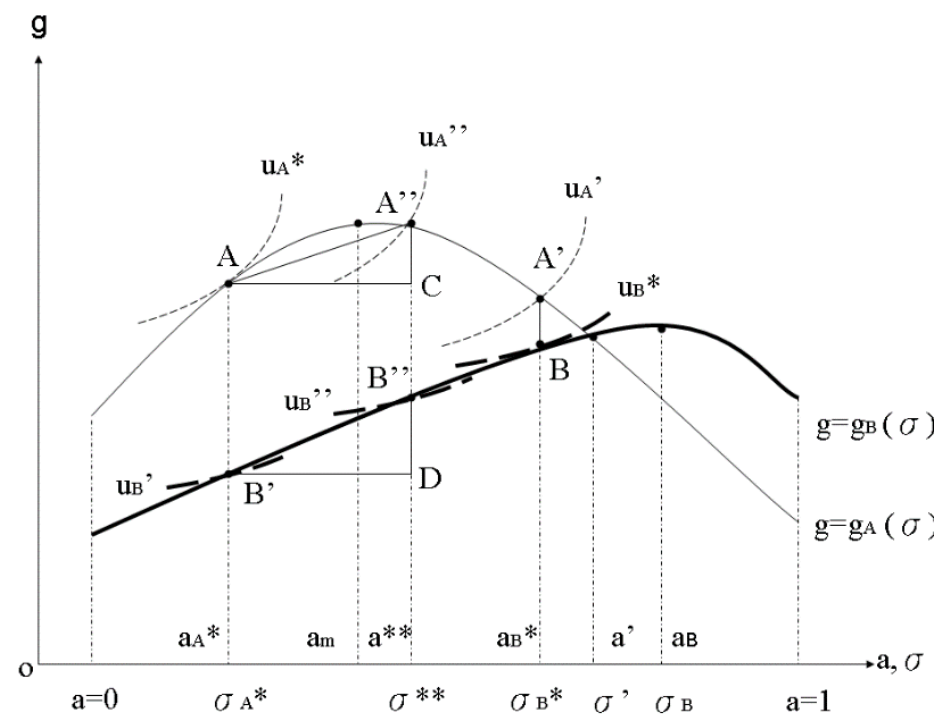

Figure 4. Diagram of decision-making regarding openness

Source: Sheng, L. (2012) Rethinking the Impacts of Foreign Investors on Urban Development: The City of Macao. "Annals of Regional Science”, 49, 73-86. Figure 3. 
If tourist city $A$ is allowed to make its choice freely, it will optimally choose the tradeoff point $A$, with maximum level of utility $u_{A}{ }^{*}$. However, point $A$ also implies control over the flow of foreign factors of production at the level of $\left(1-a_{A}^{*}\right)$. It will not satisfy $B$ since $B$ now has to operate at point $B$ ' and obtain only utility $u_{B}$ ', which is clearly sub-optimal. On the other hand, if allowed to choose freely, $B$ will choose point $B$, enjoying the highest level of utility $u_{B}{ }^{*}\left(>u_{B}{ }^{\prime}\right)$ at $B$ 's optimal level of openness, $a_{B}{ }^{*}$. Now the conflict of interests is apparent: in pursuing their respective and different optima, the interests of A and B are opposed. It is a near-zero-sum game with no possibility of Pareto improvement for any party.

However, some sort of equilibrium determining the ultimate level of openness, $a^{* *}$, must be attained in practice via negotiation, depending on the different groups' relative bargaining powers. $B$ 's explicit pressure or implicit influence on $A$ for liberalization will hurt $A$ by pushing its utility down to $u_{A}$ ' $\left(<u_{A}{ }^{*}\right)$ at point $A^{\prime}$. After moving from their respective optima (points $A$ and $B$ ) to each equilibrium (points $A$ " and $B$ "), $A$ has to accept a drop in utility by $\left(u_{A}{ }^{*}-u_{A}\right.$ ") $)$ while $B$ also faces a fall in utility amounting to $\left(u_{B}{ }^{*}-u_{B}{ }^{\prime \prime}\right)$. These two losses are the price paid by each party for the compromise that leads to more side effects yet higher growth for $A$ (from point $A$ to point $A$ ") and slower welfare growth yet lower side effects for $B$ (from point $B$ to point $B$ "). The analysis will be more realistic when compared with the original openness at $a_{A}{ }^{*}$; namely, $B$ 's push for greater openness in $A$ and subsequent negotiation between both parties lead to two triangles of tradeoff change: $A A$ " $C$ for $A$ and $B^{\prime}{ }^{\prime}{ }^{\prime \prime} D$ for $B$ in Figure 4. Tourist city $A$ experiences welfare loss in the $A$-to- $A$ " move since growth gains are overwhelmed by side effect costs due to its vulnerability to the excess part of tourism, foreign investment, and foreign labors inflow following a reluctant rise from $a^{*}{ }_{A}$ to $a^{* *}$. Foreign investor $B$ enjoys a welfare increase equal to $\left(u_{B}{ }^{\prime \prime}-u_{B}{ }^{\prime}\right)$ in the $B^{\prime}$-to- $B$ ", move since stronger growth outweighs the increase in side effects.

From the two tradeoff-change triangles, it follows, in theory, that wide openness in tourist cities can induce complementary tradeoffs between growth and side effects for both tourist cities and foreign investors through negotiation. The relative bargaining power of each party is affected by their rates of time preference, and their degrees of dependency/dominance in political/economic relations. The earlier theoretical analysis predicts that the cross-city tradeoff between growth and side effects may be complementary due to the $c$-effects on policy preferences or substitutable due to the $b$-effects on opportunity risk. Therefore, the overall tradeoffs, after including $B$ 's pressure on $A$, are a comprehensive reflection of complex interactions among 
the $b$-effects, the $c$-effects, and the bargaining effects. Yet this issue is largely a matter of empirics rather than analytics. If data show a substitutable tradeoff trend, we can infer that the $c$-effects plus the bargaining effects must have been dominated by the $b$-effects. In any case, one can see clearly that if the city allows a foreign investor's interests to be overly represented in its policy making, there is always a risk of compromising the city's interests. On the part of the foreign investor, a foreign investor will always try to influence the city to be more open than it should be.

\section{APPLICATION OF POLITICAL ECONOMY MODELS: MACAO}

In this section, Macao is adapted as a case study for us to apply the growth models that reveal the delicate relationships between foreign investors and the host community. Dialectically, the government of the host city has the incentive to pursue greater openness at the expense of the lowest possible side effects, while the struggle between the host city and the foreign investors shapes the host city's attitude towards the level of openness.

The city of Macao is one of China's two special administrative regions (SAR), and it enjoys legislative, executive, and judicial power constitutionally independent from Beijing in addition to having its own currency. With a tiny territory of only $30.2 \mathrm{~km}^{2}$ and a population of over 600,000 people, the backbone of Macao's economy is tourism, especially gaming, with tourist spending making up around 75\% of Macao's GDP. Nearly half of Macao's labor force is employed in the tourism sector, and around $75 \%$ of public revenues are generated by the gaming industry (Sheng 2014). Due to the territorial and population size, as well as the extreme dependence on the tourism, Macao can be considered as a relatively vulnerable tourist city. More precisely, it is the bold line in the Figure 1.

\subsection{Spectacular growth of the alluring host city}

Macao is a free port without any control over foreign capital investment. In fact, the government of Macao provides numerous foreign investment facilitation measures. The city reported a GDP of 430 billion Patacas ( 8 Patacas for 1 USD) in 2013 and became one of the world's richest economies. Macao has been experiencing a spectacular economic boom since 2002, with an average GDP growth of $20 \%$ annually. Such an economic boom is consistent with the growth model (Figure 2) we develop above, because the main reason for the ongoing boom is that its gaming 
industry was liberalized to foreign investors in 2002. With this broader opening, huge amounts of foreign investment have been flowing into the city. While net foreign capital inflow (capital inflow minus outflow) amounted to USD160 million in 2001, this increased to USD2115 million in 2013. The level of openness $(a)$ of Macao has been continuously increasing which drives the economic growth to increase along the $g=g_{b}(\sigma)$, as shown in Figure 2. The reason behind the economic boom in Macao should be more comprehensively explained by applying the model as shown in Figure 3. To some extent, the increased carrying capacity is contributed to by the capital inflow. For instance, the city has become a mega-construction zone with dozens of new casinos and hotels appearing in the span of a few years. Macao's world-class tourism facilities drew the attention and curiosity of nearby regions and tourist arrivals increased from 11 million in 2002 to 31 million in 2013. The advanced construction improved the efficiency of the land use, making it possible to entertain more visitors than before. With 380 billion Patacas in gaming revenue, Macao was by far the world's largest casino city in 2013. With a buildup of infrastructure and the adaptive attitude of local people to overcrowding, the tourism carrying capacity of Macao rose to 27 million visitors in 2007 (Sheng and Tsui 2009a). The vulnerability of Macao to the side effect $(b)$ is lower as shown in Figure 3, point $b$ moving at the curve $g^{*}=g(b)$ from $b$ to b'. As a result, the curve $g=g_{b}(\sigma)$ shifts outward, which is $g=g_{b},(\sigma)$. At a given level of $\sigma$, $g=g_{b},(\sigma)>g=g_{b}(\sigma)$. Simultaneously, the curve at the delta quadrant shifts from $\sigma=\sigma_{b}(a)$ to $\sigma=\sigma_{b},(a)$, which implies the same situation as shown in the right panel in Figure 1.

\subsection{The inevitable side effects borne by a tourist city}

Consistent with the theoretical models, the empirical evidence of the side effects of openness have been proved in the case study of Macao. A city's degree of openness to capital, tourist visitors and immigration has inescapable side effects. For instance, the tourism carrying capacity was again exceeded in 2008 (Sheng and Tsui 2009a). Also, to support the fast growing tourism industry, large amounts of foreign labor has been invited to the city. From 2002 to 2013, the number of guest workers increased from 23,460 to 185,207 accounting for nearly half of Macao's total employment (Sheng and Zhao, in press). The previously peaceful small town has evolved into a crowded and noisy multicultural metropolis. The side effects function 
can be described as $\sigma=\sigma(a, b)$, where $\frac{\partial \sigma}{\partial \alpha}>0$ and $\frac{\partial \sigma}{\partial b}>0$. In this case, $b$ (the vulnerability of a city to side effects) has increased due to the congestive tourist visitors and the imported labor, which ultimately makes $\frac{\partial \sigma}{\partial b \uparrow}$.

Besides the openness to tourist visitors and immigration, the openness to capital also contributes to the side effects to a city. Here we use Figure 2 to examine the case of Macao. The opportunity curve (concave) $g=g_{b}(\sigma)$ implies that $\frac{\mathrm{dg}}{\mathrm{d} \sigma}=\frac{G^{\prime}(a)}{\sigma_{b^{\prime}}(a)}>0$ when $a<a_{m}$ and $\frac{\mathrm{dg}}{\mathrm{d} \sigma}=\frac{G^{\prime}(a)}{\sigma_{b^{\prime}}(a)}<0$ when $a>a_{m}$ The model indicates that as the level of openness increases, the side effects would become more severe, which reflects the current situation of Macao. Though Macao is praised as an 'economic wonder' and a 'great success of one country, two systems', serious side effects have been developing in the city during the boom years such as leakage, inflation, real estate overheating, 'Dutch disease', overdependence on the gaming industry, crowding out of local business, negative influence on the local youth, environmental degradation, deteriorating public order, etc. From 2002 to 2013, trade deficits increased from 1,397 million Patacas to 85,070 billion Patacas, total real estate transactions increased from 5,069 million Patacas to 82,098 million Patacas, the gaming tax as a percentage of GDP increased from $14.16 \%$ to $26.14 \%$, the number of company closures increased from 99 to 557, the number of school drop outs increased from 209 to 791, mortality from respiratory illness increased from 172 to 267, the number of noise complaints increased from 2,515 to 5,579 , and the number of criminal cases increased from 9,088 to 14,961 (Sheng 2014).

\subsection{The influence of foreign investors on Macao's openness}

Macao is an estimable case to study (Figure 4) the struggle between the host city and the foreign investors in terms of the level of openness because of its unique social characteristics. What should be emphasized in Figure 4 is the result of the level of openness $\left(a^{* *}\right)$ after the bargaining between the host city and the foreign investors is not necessarily $a^{* *}=\frac{a_{B^{*}}+a_{A^{*}}}{2}$, which depends on who is in the dominant position. The overwhelming openness is gradually pushing $a^{* *}$ close to $a_{B^{*}}$ which has been proved by the inextricable side effect $\sigma$ as shown above. We will elaborate on how or what 
are the factors that "foster" the foreign investors to be in a dominant position in this near zero-sum game.

Macao is a place characterized by the population's political indifference in general and the dominance of business elite over economic, social and political life. The interests of the business elite, in particular that of deeply rooted families, are strongly represented in the executive, legislative and consultative bodies. As this core beneficiary group largely profits from the foreign investment induced boom, an aggressive gaming development strategy favorable to foreign investors seems to be inevitable. On the one hand, foreign investors provide $25 \%$ of all the jobs, and provide $60 \%$ of all the public revenue (Sheng and Tsui 2009b). Moreover, the majority of local businesses is commercially closely connected to them if not economically dependent on them. On the other hand, personal interdependence between powerful foreign investors and powerful local people may be much closer than what ordinary people believe. Up to this point, although the side effect $\sigma$ becomes more severe as the level of openness $a^{* *}$ come closer to $a_{B^{*}}$, the powerful groups who have the right to make the decision are actually willing to reach this result. Taking advantage of the political apathy of the local residents, the powerful groups make ordinary people bear relatively heavier side effects such as inflation and congestion. The delicate relations between powerful groups and foreign investors will be revealed with the following facts. Right after gaming liberalization in 2002, a former Macao government's high-ranking officer who also participated in the selection of gaming concessionaires, became a top manager in Venetian Macau, causing widespread suspicion about the dubious connections between local government officials and foreign investors (Luo, Gouch, and Wong 2012). In 2013, the former CEO of Venetian Macau sued his former Boss Sheldon Adelson in the US. Interestingly during the court process, the CEO mentioned an episode that a locally highly respected politician allegedly received 300 million US\$ in exchange for the Macao government's approval for Venetian Macau to sell a real estate worth US\$1.4 billion. More interestingly, the same CEO revealed that for many years, Adelson had systematically been collecting Macao's top politicians' personal scandals, in order to blackmail them when necessary in the future (Zhou, Lu and Yoo 2014). It was also reported that Venetian Macau subcontracted a number of its casino VIP rooms to the influential Chinese mafia bosses who are seriously involved in money laundering, human trafficking, bribery and killings (Chan and Tan 2014). Originally, only three gaming licenses were allowed in Macao 
according to the concessionaire contracts liberalizing Macao's casinos to foreign investors. However the Macao SAR government later approved the subcontracting of these licenses to other gaming firms. Another three gaming sub-concessionaires emerged with a number of additional casinos. While the Macao SAR government did not levy any extra fees on the newcomers, the Wynn Group, earned US $\$ 900$ million by subcontracting its Macao gaming license to the Australian PBL group with the Macao government's official approval (Bloomberg 2014). Moreover, it was later reported that Steve Wynn paid US\$50 million to a Taiwanese businessman who was allegedly well-connected to top politicians in Macao to secure a piece of land officially already granted to him (Beinart 2014).

The benefit-based relationships between the local powerful groups and those foreign investors are not enough to feed the ambition of the latter. The bargaining power of the foreign investors gets stronger through their strategy to manipulate the politics in mainland China. The power of the foreign investors can also be observed in their dubious relationships with certain mainland Chinese politicians. In 2012 Hong Kong businessman Richard Suen sued Sheldon Adelson for breaking his promise to pay him several hundred million dollars and $2 \%$ of shares of Venetian Macau, for his successful effort in lobbying China's former top politicians responsible for Hong Kong and Macao affairs to make Macao's gaming liberalization to foreign investors and free individual travel scheme possible (Blumental 2013). Interestingly another version of the story is that Sheldon Adelson, at the Chinese government's requests, actively lobbied the US government and legislature not to hinder Beijing's Olympic bid and not to pass a resolution calling for a boycott of the Beijing Olympics. Adelson's 'friendship' seems to have won the favor of China's top leaders and may possibly have played a decisive role in making the gaming liberalization in Macao possible (Associate Press 2013). The strange stories involve a number of top politicians in China, in the US, and in Macao. It was also reported that family members of deeply rooted families both from Macao and mainland China are employed in foreign casinos at senior positions (Eglash 2013).

Foreign casinos also seem to be successful in lobbying the Chinese central and local governments for their financial interests in Macao. Venetian Macau broadcast its advertisements on China's state TV during primetime, promoting its luxury casinos in Macao. It established its own fleet between Hong Kong and Macao, although the sea around Macao belongs to China, not Macao (Hunt 2013). Sands also negotiated with Macao's neighboring city Zhuhai on the development of Henqin Island, which is connected to Macao by bridge. It also revealed its intention to 
expand its casino empire by integrating Macao and Zhuhai, which seems to have been applauded by politicians in both cities. Foreign investors' lobbying activities and political manipulation are clearly conducted with the ultimate goal of maximizing profits (Liu 2012). Together with the Macao SAR government, foreign investors have made efforts to bring in huge numbers of tourists, without considering that Macao is a small territory with a limited tourism carrying capacity. The biggest success for these investors was convincing China to ease its restrictions on people traveling from mainland China to Macao; since 2003, Chinese citizens in the rich provinces' major cities can travel to Macao after completing a simple application. The number of Chinese tourists has increased from 1.65 million in 1999 to over 18 million in 2014, and they have become the biggest and highest spending consumer group in Macao's gaming industry. According to research by the Institute for Tourism Studies in 2003, Macao's tourism carrying capacity was around 15 million tourists. This number was exceeded in 2004 with around 17 million tourists. As we mentioned before, although with a buildup of infrastructure and the adaptive attitude of local people to overcrowding, the tourism carrying capacity of Macao rose to 27 million visitors in 2007, which was again exceeded in 2008 (Sheng and Tsui 2009a).

However, the dominate position for foreign investor where $a^{* *}>\frac{a_{B^{*}}+a_{A^{*}}}{2}$ that we presented above can also be shaped by the political consideration of the mainland China, which has become increasingly disturbed with the scale of gambling by its residents travelling to Macau, particularly government officials. A source of considerable concern is that US\$2 billion is annually gambled away by serving Chinese government officials visiting Macao. Beijing had reason to be concerned that gambling fueled corruption because most officials would not have earned the kind of salaries to be able to play the casinos. In addition, it was illegal for mainland Chinese to transfer more than US\$50,000 a year to Macau to gamble (Lague and Greenless 2007). The Chinese government's crackdown on corruption included the strict enforcement of a longstanding ban on travel to the gambling haven by public officials and high-spending punters, hitting casino profits in Macao. Most recently, mainland China had a further source for anxiety however, that Chinese officials who gambled, and particularly those who lost and ran up debts, would be open to pressure and inducements by foreign intelligence agencies. Mainland China saw this as part of an effort particularly by the US to influence events in Macao (O'Keeffe and Berzon 2012). In fact, for many years the Chinese government refused to allow the US to open a consulate in the territory because it regarded it as an American 
attempt to interfere in Macao local politics. There was a suspicion that the US would become more involved in local Macao politics if it were granted a diplomatic presence. Some Chinese officials strongly suspected that foreign casinos in particular Venetian Macau was behind the US diplomatic initiative (Pettersson 2013). In general US-owned casinos in Macau such as Sands, Wynn and MGM are viewed as part of a broader push for American influence and interference, not only in Macao, but also in the region.

Chinese suspicions of US intentions in the territory were not new. Chinese officials viewed American pressure after 9/11 to tighten regulation of Macao banks to combat money laundering as being akin to submission to US government inspection of Chinese sovereign interests. But it was a single event several years later that raised Chinese suspicions about the role of the US casinos in Macao. Beijing seemed to be shocked and stunned at the detail and accuracy of a US government report which identified Macao as a key connection in money laundering by North Korea (Klingner 2007). The US investigation into banking in Macao is also likely to have included electronic monitoring. There is a widely held perception amongst officials that Venetian Macau serves the interests of the US government in Macao. In 2005, the US government announced that the Macao-based Delta Asia Bank had been involved in a North Korean money laundering scheme. This statement and the following sanctions cut off almost all of the bank's international connections, and the owner of the bank, a Chinese national legislator and former Chief Executive candidate supported by the Chinese central government - a very influential and respected 'patriot' in Macao was ruined overnight. While officially blaming and punishing Delta Asia Bank, the US government also revealed that it would further investigate the Chinese government-owned Bank of China. In the same year, US customs inspected Macao factories concerning the possible violation of import quotas in collaboration with China and threatened the withdrawal of beneficial treatment for Macao. In 2007, the US government put Macao on its 'observation list' concerning human trafficking from China to Western countries. While the US accusations may have some ground, it seems that while Macao is opening up economically, it is also falling into a sea of international political turbulence (Reuters 2014).

As the newest development, Venetian Macau's former CEO Steve Jacobs is now suing his former boss Sheldon Adelson for wrongful dismissal in a Nevada district court. Jacobs has alleged in court documents that Adelson demanded him to use improper leverage against senior government officials in Macao to promote the company's business interests. Adelson demanded secret investigations against Macao top officials, in particular the Chief 
Executive at a time when Adelson was deeply concerned about increasing restrictions on the growth of the gambling industry in Macao and the difficulties he was running into selling property as a result of the desire by the Macao and mainland Chinese authorities to reduce the enclave's dependency on gambling. The company wanted to gather information on Macao's chief executive, in particular to identify any weakness which might compromise his ability to function or his loyalty to mainland China. Jacobs further points out that that historically Venetian Macau had made use of a 'middleman' to develop mainland China relationships using wide range of monetary incentives. It is believed that this middleman had successfully opened the China door for Sheldon Adelson through the late 1990s, building up a circle of friends consisting of a number of influential political figures and key persons in charge of Hong Kong and Macao affairs. However, this middleman began actively lobbying against Venetian Macau after 2004 because he considered himself not having been properly paid for his contribution to his US boss (Geier 2015).

The tourism boom, created with the help of massive foreign investment, has made fewer contributions to the local community than is generally assumed, not to mention its negative social-environmental impacts on the city of Macao. This has led to sharp conflicts between locals, who do not directly benefit from the tourism boom and greatly suffer from its side effects, and the foreign investors together with the local politicians, which grant generous support to foreign investors. Blame has been laid on the Macao government for its 'betrayal' of local interests to foreign capitalists. Conflicts between the beneficiary and non-beneficiary groups escalated in a series of protests, in which politicians were accused of "making themselves rich via illegal channels" and "betraying Macao to foreign investors" (Wan 2012). After all, such escalating social grievance can also be accounted as the side effect of the increasing level of openness. The side effects of openness are borne largely by the host city shown in Figure 4: host city $A$ 's the utility function $u=u_{A}(\sigma, g)$ is steeper than foreign investor $B$ 's utility function $u=u_{b}(\sigma, g)$. The result of bargaining $a^{* *}$ creates the interception (not tangent because of $a_{A}{ }^{*}<a^{* *}<a_{B}{ }^{*}$ ) of their utility function and their opportunity function: $A$ " 'and $B$ ". The magnitudes of the welfare loss that city A experience (in the case Macao) can be interpreted as the area of the triangle $\triangle A A^{\prime \prime} C$ while the foreign investors enjoy a welfare increase equal to the area of triangle $\triangle B^{\prime} B^{\prime \prime} D$. Therefore, the property of bargaining can be considered as a near zero-sum game. The application of a growth model entails the comprehensive culture and the political background in the case of 
Macao. For one thing, the struggle between the host city (here referring to Macao) and the foreign investors about the level of openness is sophisticated. The foreign investors strive for the dominant position by manipulating the economic and political interests among Macao's powerful groups and mainland China. For another, the result of the level of openness can also be influenced by the consideration beyond economic perspectives, more precisely, the political struggle between China and the US.

\section{CONCLUDING REMARKS}

The theoretical construct proposed by this paper makes a unique contribution to our understanding of urban policy-making since the role of foreign investors cannot be overlooked or underestimated in reality. The host community is never homogenous and in harmony in the face of rapid tourism growth. While beneficiary groups benefit a lot from a boom in tourism and shoulder the side effects distributed to them, non-beneficiary group may experience the opposite. Therefore, different preferences with regard to a city's openness arise: the beneficiaries prefer more openness and the non-beneficiaries prefer less openness. If so, foreign investors and local beneficiaries may find common interests and co-operate with each other to a certain extent. Also, regional government (one level up from the city) and central government may have their own preferences with regard to the city's openness. They consider the issue in a broader regional and national context, and in many cases, it may not be in accordance with the preferences of the vast non-beneficiary group in the city. Moreover, foreign investors, especially mega-multinational enterprises, possess considerable political influence on their international partners. Backed by their own governments, they may put considerable political pressure on invested cities/countries to bargain for preferable treatment. If this is the case, a host community's interest may even be 'betrayed' for political deals at the international level, as happened in the case of Macao presented here.

Although the present study focuses on the 'dark side' of foreign investment in the context of urban development, we do not want to give the impression that foreign investment should be negatively judged. We simply attempt to counterbalance a widely accepted liberal doctrine with regard to foreign investment. It is understandable that foreign investors are profitdriven and prefer broad openness for their cities of interest. What should be focused on is the role of the decision makers in the city itself. They can choose to either pursue wider openness by reinforcing and facilitating 
foreign investors' efforts, or place certain controls on openness in order to regulate the city's overall growth. While the former may result in serious side effects, the latter can make the sustainable development of the city possible.

\section{REFERENCES}

Associate Press, Sands loses \$70M in lawsuit over Macau license. AP, May 14, 2013.

Boukas, N., Ziakas, V., Impacts of the Global Economic Crisis on Cyprus Tourism and Policy Responses, "International Journal of Tourism Research", 15(4), pp. 329-345, 2013.

Beinart, P., Sheldon Adelson's Culture of Hate. Haaretz, April 2, 2014.

Bloomberg, Billionaire Lau Guilty of Bribery, Corruption in Macau. Bloomberg, March 14, 2014.

Chan, V., Tan, C., Macau Anti-graft Agency Probes Wynn Palace Land Deal. Bloomberg, July 11, 2014.

Choi, K., Harrigan, J., Foreign Investment and the Operations of Multinational Firms: concepts, History and Data. Handbook of International Trade, pp. 285-319, 2008.

Eglash, R., How US Billionaire Sheldon Adelson is Buying up Israel's Media. The Washington Post, May 1, 2013.

Geier, B., Why Sheldon Adelson is Going to Spend Tens of Millions on His Favored Republican, September 10, 2015.

Hill, H., Foreign Investment and East Asian Development. Asian-Pacific Economic Literature, 4(2), pp. 21-58, 1990.

Hunt, K., The Dark Side of Asia's Gambling Mecca. CNN, June 18, 2013.

Jin, J. J., Wang, Z. S., Liu, X. M., Valuing Black-faced Spoonbill Conservation in Macao: A Policy and Contingent Valuation Study, "Ecological Economics", 68(1/2), pp. 328-335, 2008.

Klingner, B., Banco Delta Asia Ruling Complicates North Korean Nuclear Deal. Heritage Foundation Memo on Asia No. 1398, 2007.

Lague, D., Greenlees, D., Squeeze on Banco Delta Asia Hit North Korea Where It Hurt. The New York Times, January 18, 2007.

Lei, K. P., Wang, Z. S., Ton, S. S., Holistic Energy Analysis of Macao, "Ecological Engineering", 32(1), pp. 30-43, 2008.

Lew, A., Hall, M., Williams, A. M., Environmental Impacts of Tourism, "A Companion to Tourism”, pp. 450-461, 2008.

Liu, M. Graft or Guanxi, "Newsweek”, August 20, 2012.

Luo, M., Gouch, N., Wong, E. Scrutiny for Casino Mogul's Frontman in China, "The New York Times", August 13, 2012.

O'Keeffe, K., Berzon, A., Fired Executive Rankles Casino Business-Former Sands China Chief's Wrongful Termination Suit Puts Spotlight on U.S. Operators in China's Gambling Enclave, “The Wall Street Journal”, December 5, 2012. 
Pettersson, E., Adelson Returns to Stand in \$328 Million Macau Deal Suit. Bloomberg, Apr. 9, 2013.

Reuters, Macau Graft Agency Probes Wynn Land Deal. Reuters, July 11, 2014.

Rho, Y., Rodrigue, J., Growing into Export Markets: The Impact of Exporting on Firm-level Investment in Indonesia, 23(1), pp. 62-85, 2015.

Sheng, L., Effects of Foreign Expansion on Local Growth: The Case of Macao, "European Planning Studies", 22(8), pp. 1735-1743, 2014.

Sheng, L., Tsui, Y. M., A General Equilibrium Approach to Tourism and Welfare: The Case of Macao, "Habitat International", 33(4), pp. 419-424, 2009a.

Sheng, L., Tsui, Y. M., Casino Booms and Local Politics: The City of Macao, "Cities 26(2)", pp. 67-73, 2009b.

Sheng, L., Zhao, W. B., (in press) Strategic Destination Management in the Face of Foreign Competition: The Case of Macao, "Journal of Travel \& Tourism Marketing".

Wan, Y. K., The Social, Economic and Environmental Impacts of Casino Gaming in Macao: The Community Leader Perspective, "Journal of Sustainable Tourism", 20(5), pp. 737$-755,2012$.

Wan, Y. K., A Comparison of the Governance of Tourism Planning in the Two Special Administrative Regions of China - Hong Kong and Macao, "Tourism Management", 36, pp. 164-177, 2013.

Wan, Y. K., Kim, S. S., Elliot, S., Behavioral Differences in Gaming Patterns among Chinese Subcultures as Perceived by Macao Casino Staff, "Cornell Hospitality Quarterly", 54(4), pp. 358-369, 2013.

Winters, P., Corral, L., Mora, A. M., Assessing the Role of Tourism in Poverty Alleviation: A Research Agenda, "Development Policy Review", 31(2), pp. 177-202, 2013.

Zhou, Y., Lu, T., Yoo, J. E., Residents' Perceived Impacts of Gaming Development in Macau: Social Representation Perspectives, "Asia Pacific Journal of Tourism Research", 17(5), pp. 579-599, 2014.

Received: December 2015

Acknowledgments: This research is funded by the University of Macau Research Committee, ref. MYRG2017-00093-FSS. 